\title{
Functional interactions between the pelle kinase, Toll receptor, and tube suggest a mechanism for activation of dorsal
}

\author{
Jacqueline L. Norris ${ }^{1}$ and James L. Manley ${ }^{2}$ \\ ${ }^{2}$ Department of Biological Sciences, Columbia University, New York, NY 10027
}

\begin{abstract}
A complex signal transduction pathway functions in the early Drosophila embryo to establish dorsal-ventral polarity. Activation of this pathway results in the nuclear transport of the protein dorsal (dl), a member of the rel/NF-KB family of transcription factors. Genetic studies have identified three intracellular components whose activity is required for activation of $\mathrm{dl}$ : Toll, a transmembrane receptor; pelle (pll), a serine/threonine protein kinase; and tube, a protein of unknown function. Here we examine the activities of these proteins when coexpressed in Drosophila Schneider cells. Coexpression of pll with dl enhanced dl nuclear localization and resulted in a modest increase in transcriptional activity. However, when pll was coexpressed with a specific mutant derivative of Toll (TlNaeI), although not with wild-type Toll, a striking synergistic activation of dl was detected. Unexpectedly, coexpression of pll plus TlNaeI, in the absence of dl, resulted in a similar synergistic activation of a GAL4-tube fusion protein. Based on these and other results, we propose a model in which pll receives a signal from activated Toll and phosphorylates tube, which then participates directly in dl activation.
\end{abstract}

[Key Words: Drosophila; signal transduction pathway; rel/NF-kB proteins; phosphorylation; transcriptional regulation]

Received January 2, 1996; revised version accepted February 8, 1996.

Dorsal-ventral (D/V) polarity is established in the early Drosophila embryo by the formation of a nuclear concentration gradient of the maternal morphogen dorsal (dl). This gradient arises from the selective nuclear transport of dl into ventral but not dorsal nuclei (Roth et al. 1989; Rushlow et al. 1989; Steward 1989). dl is a member of the rel/NF- $\mathrm{kB}$ family of transcription factors and, like the other members of this family, its activity is regulated by subcellular localization (for review, see Govind and Steward 1991; Rushlow and Warrior 1992; Norris and Manley 1995a). Genetic screens have identified 11 genes that are required for regulating $\mathrm{dl}$ nuclear transport and activity. Seven of these are required for the generation of a signal that is localized in the perivitelline fluid on the ventral side of the embryo (Stein et al. 1991; Stein and Nüsselein-Volhard 1992; Morisato and Anderson 1994; Schneider et al. 1994), whereas the other four are required for transmitting this signal from the plasma membrane to $\mathrm{dl}$. There are several parallels between this intracellular pathway and the signal transduction pathways that regulate NF- $\mathrm{kB}$. In fact, $\mathrm{dl}$ and the closely related protein, Dif (Ip et al. 1993), plus the four intracellular signaling components, are known to function zy-

${ }^{1}$ Present address: Lineberger Comprehensive Cancer Center, University of North Carolina at Chapel Hill, North Carolina 27599 USA gotically during the Drosophila immune response (Lamaitre et al. 1995).

The Toll gene encodes a transmembrane protein that serves in the embryo as the receptor for the ventrally localized signal (Hashimoto et al. 1988, 1991; Morisato and Anderson 1994; Schneider et al. 1994). Toll's intracellular domain is similar to the cytoplasmic domain of the interleukin-1 receptor (IL-1R) (Schneider et al. 1991). Several agents, including the cytokine interleukin-1 (IL1), lead to the activation of NF-kB (Shirakawa et al. 1989; for review, see Siebenlist et al. 1995/. The similarity between Toll and IL-1R suggests that they may use similar pathways to transmit their signals, although the mechanism of signal transduction is not well understood. However, there is evidence that both may, in some cases, utilize protein kinase A (PKA) to signal nuclear transport, as treatment of cells with IL-1 can raise cAMP levels (Shirakawa et al. 1988) and expression of Toll or PKA activates $\mathrm{dl}$ in Drosophila Schneider cells (Norris and Manley 1992).

Although the mechanism of signal transduction by Toll is unknown, it is clear that it involves dissociation of dl from its inhibitor, cactus (Roth et al. 1991; Gillespie and Wasserman 1994; Belvin et al. 1995). Activation of NF- $\mathrm{B}$ also requires dissociation from its inhibitor I $\mathrm{B}, \mathrm{a}$ protein similar to cactus. Phosphorylation of IкB was 
initially thought to disrupt the $\mathrm{I}_{\kappa} \mathrm{B} \backslash \mathrm{NF}-\kappa \mathrm{B}$ complex directly because phosphorylation of $\mathrm{I} \kappa \mathrm{B}$ in vitro destroyed its ability to inhibit NF-kB DNA binding (Ghosh and Baltimore 1990). However, in vivo experiments have shown that phosphorylation of $I_{\kappa} B$ is necessary but not sufficient for activation of NF-kB (Finco et al. 1994; Aikalay et al. 1995; DiDonato et al. 1995). Increasing evidence suggests that phosphorylation of IкB regulates its degradation, and the degradation of ІкB appears to result in the disruption of the IкB/NF-кB complex (Beg et al. 1993; Henkel et al. 1993; Miyamoto et al. 1994; Palombella et al. 1994; Traenckner et al. 1994, 1995; Brown et al. 1995). cactus is also rapidly degraded in response to activation of the signaling pathway (Belvin et al. 1995), although dl, not cactus, has been shown to be phosphorylated in response to signaling in embryos (Whalen and Steward 1993; Gillespie and Wasserman 1994).

The activities of two genes, tube and pelle (p1l), are known from genetic studies to be required downstream of Toll (Hecht and Anderson 1993). The tube gene encodes a protein with no homology to any known proteins, whereas pll encodes a serine/threonine protein kinase that is most similar to members of the raf $/ \mathrm{mos}$ family of protein kinases (Letsou et al. 1991; Shelton and Wasserman 1993). tube is initially localized to the plasma membrane of the embryo at the time when Toll is activated, although it can be detected subsequently in nuclei (Galindo et al. 1995). Also, tube can colocalize with $\mathrm{dl}$ to the nucleus in cotransfected Schneider cells (Norris and Manley 1995b). Expression of artificial gainof-function tube and pll alleles has shown that tube activity can be required upstream of pll (Grosshans et al. 1994; Galindo et al. 1995). These results suggest that tube may help transmit the signal for $\mathrm{dl}$ nuclear transport from Toll to pll, resulting in activation of pll. The in vivo targets of pll are not known, although pll phosphorylates tube, but not $\mathrm{dl}$ or cactus, in vitro (Grosshans et al. 1994).

To investigate further the role of pll, as well as Toll and tube, in $\mathrm{dl}$ signaling we have continued to use transient cotransfection assays in Schneider cells (Norris and Manley 1992, 1995b). pll, like Toll and dl but unlike tube and cactus, is not expressed endogenously in Schneider cells (J.L. Norris and J.L. Manley, unpubl.). Here we show that expression of pll can enhance nuclear localization and transcriptional activity of dl. However, coexpression of pll and a specific Toll deletion mutant is shown to result in much stronger, synergistic activation of $\mathrm{dl}$. In addition, pll activated by the same Toll derivative markedly increased transcriptional activity of a GAL4-tube fusion protein in the absence of $\mathrm{dl}$. Based on these and other findings, we discuss possible models for the interactions among the components of this signal transduction pathway.

\section{Results}

Expression of pll enhances the transcriptional activity of $d l$

As discussed above, the pll gene encodes a protein ki- nase, and $\mathrm{dl}$ is phosphorylated in response to activation of the signal transduction pathway that leads to its nuclear localization. To investigate the function of pll in this pathway, we used transient cotransfection assays, as described previously (Norris and Manley 1992, 1995b). To measure dl activity we used a 235-bp fragment from the Drosophila zen promotor $(-196$ to +39$)$ to drive expression of the chloramphenicol acetyl transferase (CAT) gene (zen-CAT200; Rushlow et al. 1989). When expressed in Schneider cells, $\mathrm{dl}$ has been shown to activate expression from zen-CAT200 in a concentrationdependent manner, which reflects, at least in part, an increase in the nuclear concentration of $\mathrm{dl}$ /Rushlow et al. 1989; see below). Although the exact mechanism by which dl activates CAT expression from zen-CAT200 has not been studied, it likely involves a potential weak dl binding site (see Norris and Manley 1995b).

Figure 1A shows the pll construct used in these experiments. The pll cDNA was cloned into an actin $5 \mathrm{C}$ vector such that the expressed protein contains an aminoterminal influenza virus HAl epitope tag (ActFlu-pll). Figure 1B shows the results of cotransfections that contained $0.4 \mu \mathrm{g}$ of Act-dl and the zen-CAT200 reporter plasmid, plus or minus ActFlu-pll. This concentration of Act- $d l$ was used because, as shown previously, CAT expression is enhanced only weakly unless other genes that can activate $\mathrm{dl}$ are cotransfected (Norris and Manley 1992, 1995b). As shown in Figure 1B, expression of pll enhanced the ability of $\mathrm{d}$ lo activate CAT expression approximately fourfold. This activation was specific to $\mathrm{dl}$, as expression of pll in the absence of $\mathrm{dl}$ had no effect on expression from zen-CAT200 (first line, Fig. 1B), nor did pll affect the ability of several other coexpressed transcriptional activators to enhance CAT expression from appropriate reporter plasmids (data not shown).

We also tested the effect of pll on the activity of two dl mutants, $\mathrm{dl} 3$ and dlQ. The protein encoded by dl3 lacks the carboxy-terminal 117 amino acids and has been shown to be constitutively nuclear in transfected cells (Rushlow et al. 1989). Expression of pll enhanced dl3's activation of CAT expression approximately threefold, suggesting that pll may induce a modification that affects not only the nuclear localization of dl but also transcriptional activity. The dlQ protein contains glutamine in place of serine at residue 312 , the potential PKA phosphorylation site. This protein is localized primarily in the cytoplasm and has only weak transcriptional activity even at high concentrations or in the presence of Toll or PKA (Norris and Manley 1992). Expression of pll did not enhance the ability of dlQ to activate CAT expression, suggesting that the PKA site is required for dl nuclear transport or activity.

\section{Expression of pll enhances dl nuclear localization}

When Schneider cells are transfected with $0.4 \mu \mathrm{g}$ of Act$\mathrm{dl}, \mathrm{dl}$ is located primarily in the cytoplasm (e.g., Rushlow et al. 1989). In contrast, when $\mathrm{dl}$ is coexpressed with Toll or PKA, dl is found primarily in the nucleus, or in both the cytoplasm and nucleus in the case of Toll /Norris and 


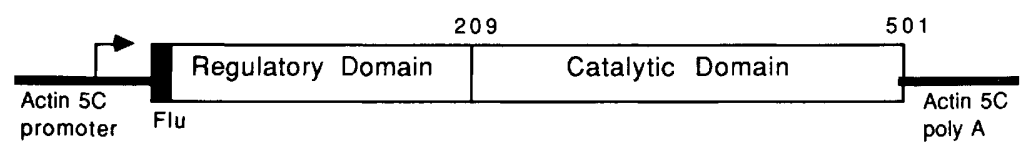

B

Figure 1. Activity of $\mathrm{dl}$ in the presence of pll. $(A)$ The pll expression vector containing the HAl epitope tag (Flu) is shown. The putative amino-terminal regulatory domain and the carboxy-terminal catalytic domain are indicated. Numbers refer to amino acid residues. $(B)$ Schneider cells were cotransfected with $0.4 \mu \mathrm{g}$ of $d l$ expression vector, $4.0 \mu \mathrm{g}$ of pll expression vector, $1.0 \mu \mathrm{g}$ of the zenCAT200 reporter plasmid, and pAct5C to bring the final concentration of expression vector to $7.0 \mu \mathrm{g}$. All transfections were normalized for differences in transfection efficiency by using copia $\beta$-gal as an internal control. Fold activation is presented as the increase in CAT activity relative to the value from the cotransfection lacking a pll expression vector.

Manley 1992). Therefore, part of the enhancement of $\mathrm{dl}$ activity induced by Toll or PKA can be attributed to the increase in the nuclear concentration of dl. Immunofluorescence assays were performed to determine whether the increase in $\mathrm{dl}$ activity in the presence of pll could also be attributable to an increase in $\mathrm{dl}$ nuclear concentration. Cells were transfected with either $0.4 \mu \mathrm{g}$ of Act$d l$ or $0.4 \mu \mathrm{g}$ of Act-dl plus $4.0 \mu \mathrm{g}$ ActFlu-pll, fixed, and stained with anti-dl antibodies. Figure $2 \mathrm{~A}$ shows that $\mathrm{dl}$ was localized primarily in the nucleus when pll was expressed. As discussed above, dlQ was localized primarily in the cytoplasm even in the presence of Toll or PKA. Because pll could relocalize wild-type (wt) dl effectively, we wanted to determine whether pll could also relocalize dlQ. Figure 2B shows that expression of pll did not enhance nuclear localization of dlQ, suggesting that the PKA site is required for $\mathrm{dl}$ nuclear localization even when translocation is induced by pll.

We have shown previously that expression of PKA enhanced dl transcriptional activity up to 15-fold (Norris and Manley 1992). Because pll and PKA are both kinases that can regulate $\mathrm{dl}$ subcellular localization we wanted to determine whether the activity of either one might affect the activity of the other. Figure 3 shows the results of cotransfecting Schneider cells with zen-CAT200 and Act-dl, plus ActFlu-pll and/or Act-PKA. PKA enhanced $\mathrm{dl}$ activity somewhat better than $\mathrm{pll}, 10$-fold as compared with 4-fold, even though dl was localized primarily in the nucleus in the presence of both pll and PKA. The $\mathrm{dl}$ activity obtained when both kinases were coexpressed was additive, suggesting that neither kinase is responsible for activating the other and that they may have different roles in the signal transduction pathway (see Discussion).

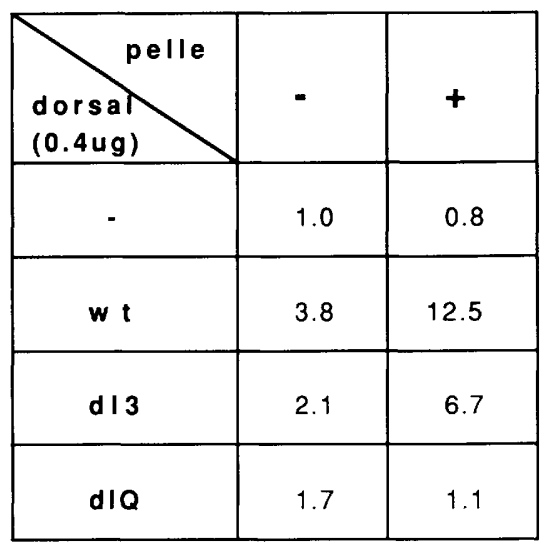

Toll and pll can functionally interact to enhance dl activity synergistically

Because activated Toll is responsible for transducing the signal that leads to dl nuclear transport in embryos, we wanted to determine whether coexpression of Toll, or one of several mutant derivatives, could enhance pll activity. Figure 4A shows the Toll constructs used, which have all been described previously (Norris and Manley 1995b). The Toll ${ }^{10 \mathrm{~b}}$ protein contains a single amino acid change in the extracellular domain that results in a constitutively active protein in embryos (Schneider et al. 1991) and elevated activity in transfected Schneider cells. The TIStuI and TlBstXI constructs contain deletions into the region of the intracellular domain that shares homology with IL-1R and encode inactive proteins. The TlNarI and TlNaeI proteins both maintain the region that is similar to IL-1R but delete part of the region that is unique to Toll. The protein produced by TINarI retains the same activity as wild-type Toll, whereas the TINaeI protein was shown to be twofold more active than wild-type Toll. The TIIC construct expresses only the intracellular domain, and the resulting protein was shown to be half as active as full-length Toll. The wild-type and mutant derivatives all accumulated to comparable levels in transfected cells (Norris and Manley 1995b; results not shown).

Figure 4B presents the results of cotransfecting Schneider cells with zen-CAT200, Act-dl, ActFlu-pll, and each of the above Act- $T l$ constructs. The dl activity detected when $T l, T l^{10 b}, T l N a r I, T I S t u I$, or TlBstXI was coexpressed with pll was additive. However, the $\mathrm{dl}$ activity observed when TlNaeI was coexpressed with pll was not only much greater than additive, it was signifi- 
A

d I
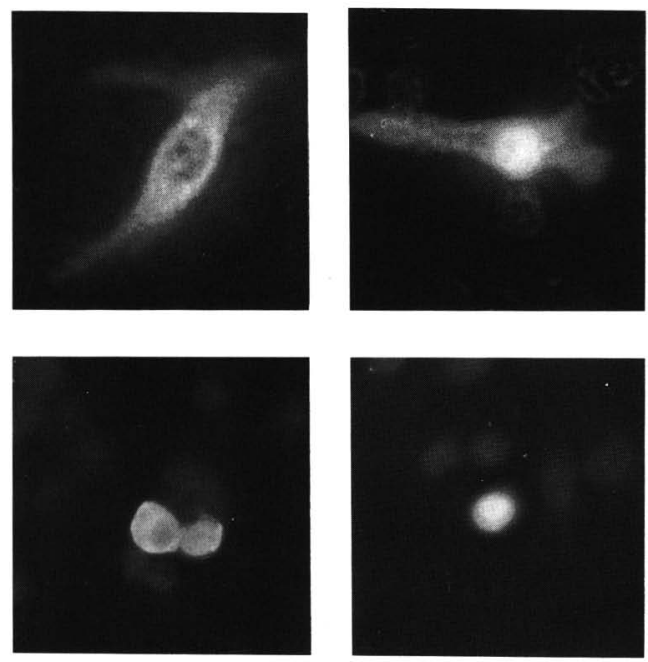

B
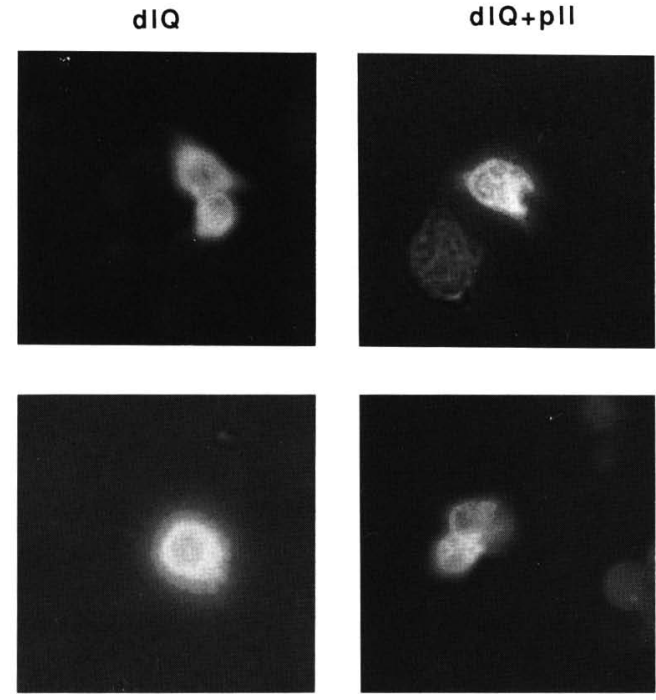

Figure 2. Subcellular localization of $\mathrm{dl}$ in the presence of pll. Schneider cells were cotransfected with $0.4 \mu \mathrm{g}$ of $d l$ expression vector alone or with $4 \mu \mathrm{g}$ of pll expression vector. $|A|$ Cytoplasmic staining of wild-type $d l$ alone and nuclear staining of wildtype $\mathrm{dl}$ in the presence of pll is shown. (B) Cytoplasmic staining of dlQ both alone and in the presence of pll is shown.

cantly greater than what would be expected from multiplying the individual activities. Therefore, TINaeI, but not full-length Toll, can function synergistically with pll to enhance dl activity. This synergy was specific for pll and TlNael, as cotransfection of Act-PKA and Act-TINaeI had only an additive effect on $d l$ activity (results not shown).

A comparison of the Toll and IL-1R intracellular domains is presented in Figure 5A. The two domains share $43 \%$ similarity and $26 \%$ identity over the entire 212 amino acid residues of the IL-1R intracellular domain and 200 residues of the Toll intracellular domain (Schneider et al. 1991). This region of similarity is re- quired for the function of both receptors (Heguy et al. 1992; Norris and Manley 1995b). Toll's intracellular domain has an additional 68 residues not found in the IL$1 \mathrm{R}$ intracellular domain. It is thus deletion of this Tollunique region that allowed Toll to interact synergistically with pll, extending the view (Norris and Manley 1995b) that this region constitutes an inhibitory domain.

To extend the study of this domain, we also tested the effect of deleting this region in Toll ${ }^{10 \mathrm{~b}}$ and TlIC. Figure $5 \mathrm{~B}$ shows the results, presented as Toll + pll synergy (see legend to Fig. 5), of cotransfections of each Act-TINaeI deletion with Act-dl, ActFlu-pll and zen-CAT200. In each case, only when the inhibitory domain was deleted was synergistic activation of $\mathrm{dl}$ detected. This synergy was specific for $\mathrm{dl}$ as cotransfection of Act-TlNaeI and ActFlu-pll with Act-z2 or Act-prd, which encode homeo domain activators (Han et al. 1989), did not affect CAT expression from the appropriate reporter plasmids (results not shown). Together, these results indicate that in the absence of the Toll inhibitory domain, Toll and pll functionally interact in a manner that results in a dramatic increase in $\mathrm{dl}$ activity.

\section{dl activity in the presence of pll and tube}

The tube and pll proteins have been shown to interact in a yeast two-hybrid system /Grosshans et al. 1994; Gal-

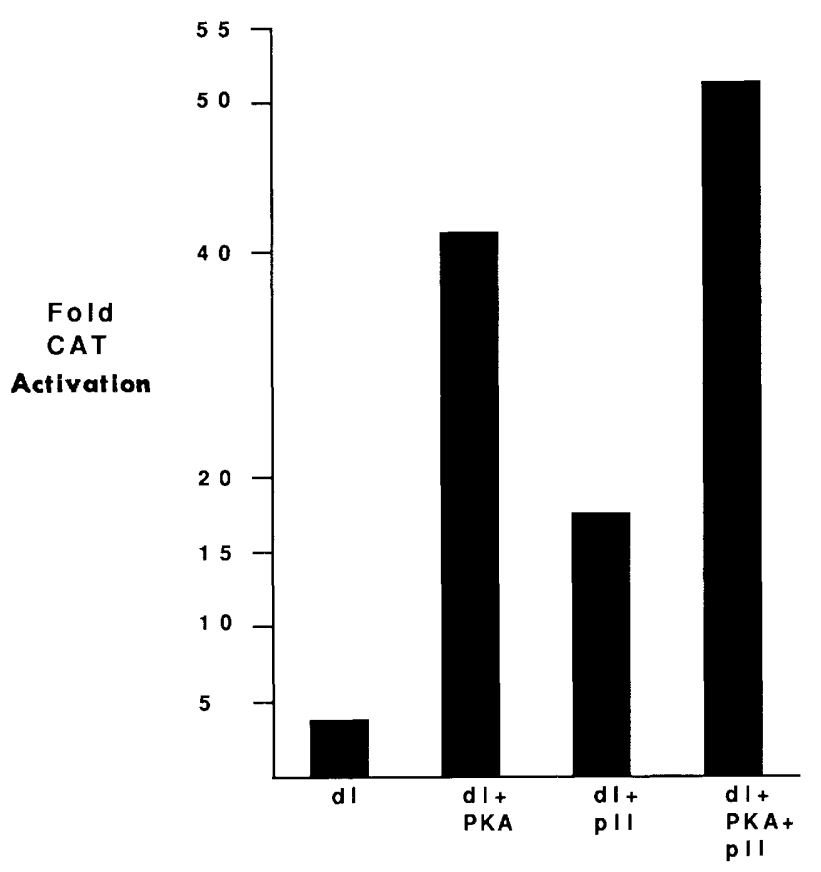

Figure 3. Activity of $\mathrm{dl}$ in the presence of PKA and pll. Schneider cells were transfected with $0.4 \mu \mathrm{g}$ of $d l$ expression vector, either $3.0 \mu \mathrm{g}$ of PKA expression vector or $3.6 \mu \mathrm{g}$ of pll expression vector alone or in combination, $1.0 \mu \mathrm{g}$ of the zen-CAT200 reporter plasmid, and pAct $5 \mathrm{C}$ to bring the concentration of expression vector to $7.0 \mu \mathrm{g}$. The activation values are expressed relative to cotransfections containing the actin $5 \mathrm{C}$ expression vector without an insert. 


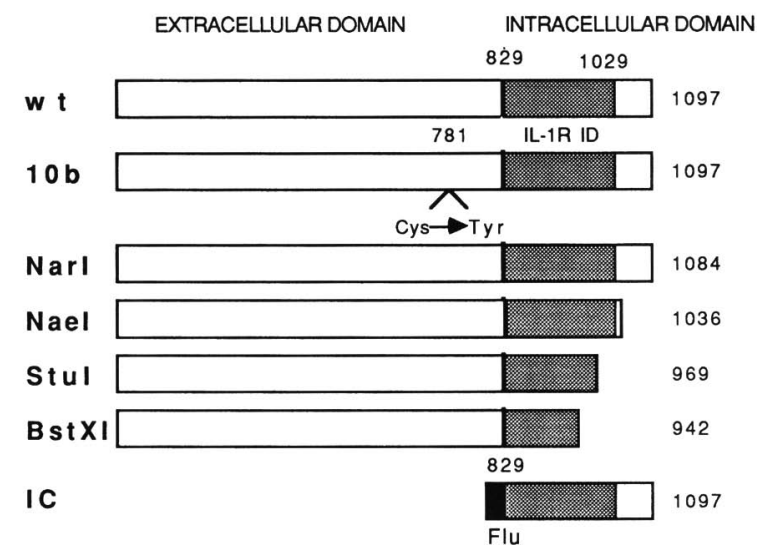

\begin{tabular}{|c|c|c|c|}
\hline $\begin{array}{l}\text { Fold dl CAT } \\
\text { Toll } \\
\text { construct }\end{array}$ & + Toll & +pll & $\begin{array}{l}\text { +Toll } \\
+p I I\end{array}$ \\
\hline w t & 4.0 & 2.5 & 5.2 \\
\hline TIIOb & 13.2 & 5.9 & 23.7 \\
\hline TINarI & 3.1 & 3.8 & 6.6 \\
\hline TINael & 8.2 & 3.1 & 65.7 \\
\hline TIStuI & 1.0 & 2.5 & 2.3 \\
\hline TIBstXI & 0.9 & 3.3 & 4.0 \\
\hline TIIC & 2.8 & 5.0 & 9.5 \\
\hline
\end{tabular}

Figure 4. Activity of $\mathrm{dl}$ in the presence of Toll and pll. (A) The extracellular and intracellular domains, the region of IL-1R homology, and the inhibitory domain (ID) are indicated on each Toll construct. Numbers refer to amino acid residues. The IC construct contains the HAl epitope tag (Flu). (B) Schneider cells were cotransfected with $0.4 \mu \mathrm{g}$ of $d l$ expression vector, $3.0 \mu \mathrm{g}$ of the indicated Toll expression vector, $3.6 \mu \mathrm{g}$ of the pll expression vector, $1.0 \mu \mathrm{g}$ of the zen-CAT200 reporter plasmid, and pAct5C to bring the concentration of expression vector to $7.0 \mu \mathrm{g}$. The activation values are expressed relative to cotransfections containing $0.4 \mu \mathrm{g}$ of the $d l$ expression vector.

indo et al. 1995). To begin to investigate the possible functional significance of this interaction, we cotransfected Schneider cells with zen-CAT200 and Act-dl plus Act-tube and/or ActFlu-pll, and the results are presented in Figure 6A. Under these conditions, dl activated CAT expression $\sim 20$-fold in the presence of pll and 15fold in the presence of tube. However, when pll and tube were coexpressed $\mathrm{dl}$ activated CAT expression by only $\sim 10$-fold, indicating that expression of pll and tube together not only did not enhance $\mathrm{dl}$ activation but had a slight inhibitory effect. To determine whether activation of the signaling pathway by TlNaeI could prevent this inhibition, Act-TINaeI was included in cotransfections. Figure 6B shows that when TlNaeI was coexpressed there was no inhibition of the ability of tube or pll to activate dl. However, tube was unable to enhance the
A

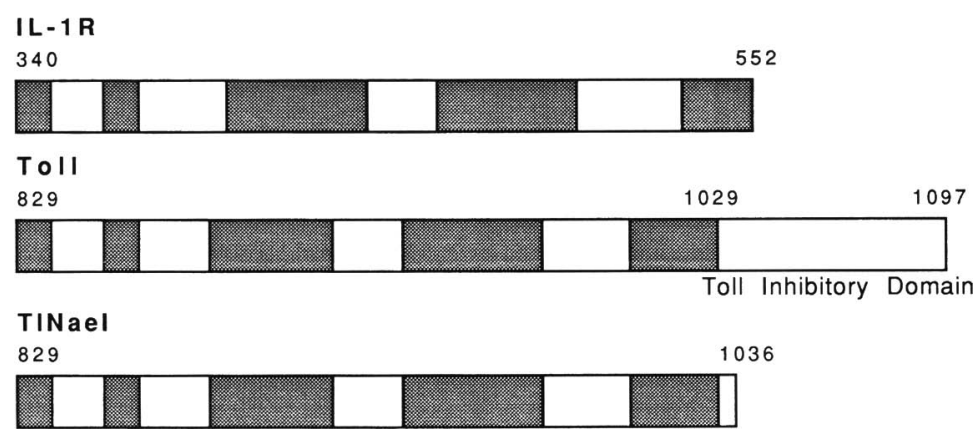

\begin{tabular}{|l|c|}
\hline $\begin{array}{c}\text { Toll } \\
\text { construct }\end{array}$ & $\begin{array}{c}\text { Toll+pII synergy } \\
\text { (TIxpII=1.0) }\end{array}$ \\
\hline w t & 0.5 \\
\hline TI10b & 0.3 \\
\hline TIIC & 0.7 \\
\hline TINael & 2.5 \\
\hline TI1ObNael & 2.0 \\
\hline TIICNael & 1.9 \\
\hline
\end{tabular}

Figure 5. Activity of $\mathrm{dl}$ in the presence of $\mathrm{dl}$ and Toll inhibitory domain deletions. $(A)$ The intracytoplasmic domains of IL-1R and Toll are shown. Regions with $>50 \%$ similarity are shaded. Numbers refer to amino acid residues. $(B)$ Schneider cells were cotransfected with $0.4 \mu \mathrm{g}$ of $d l$ expression vector, $3.6 \mu \mathrm{g}$ of $p l l$ expression vector, either $3.0 \mu \mathrm{g}$ of wild-type Tl, TINaeI, TIIC, TIICNaeI or 1.0 $\mu \mathrm{g}$ of $T 1^{1 \mathrm{Db}}, T 1^{10 \mathrm{~b}} \mathrm{NaeI}, 1.0 \mu \mathrm{g}$ of the zen-CAT200 reporter plasmid, and pAct5C to bring the final concentration of expression vector to $7.0 \mu \mathrm{g}$. The values represent how many times higher the observed value of dl activity in the presence of the indicated Toll derivative plus pll is relative to the value that would be obtained by multiplying the $\mathrm{dl}$ activities detected in the presence of either the Toll derivative or pll alone. Thus, a value of 1.0 or higher is equal to or greater than multiplicative. 


\section{B}
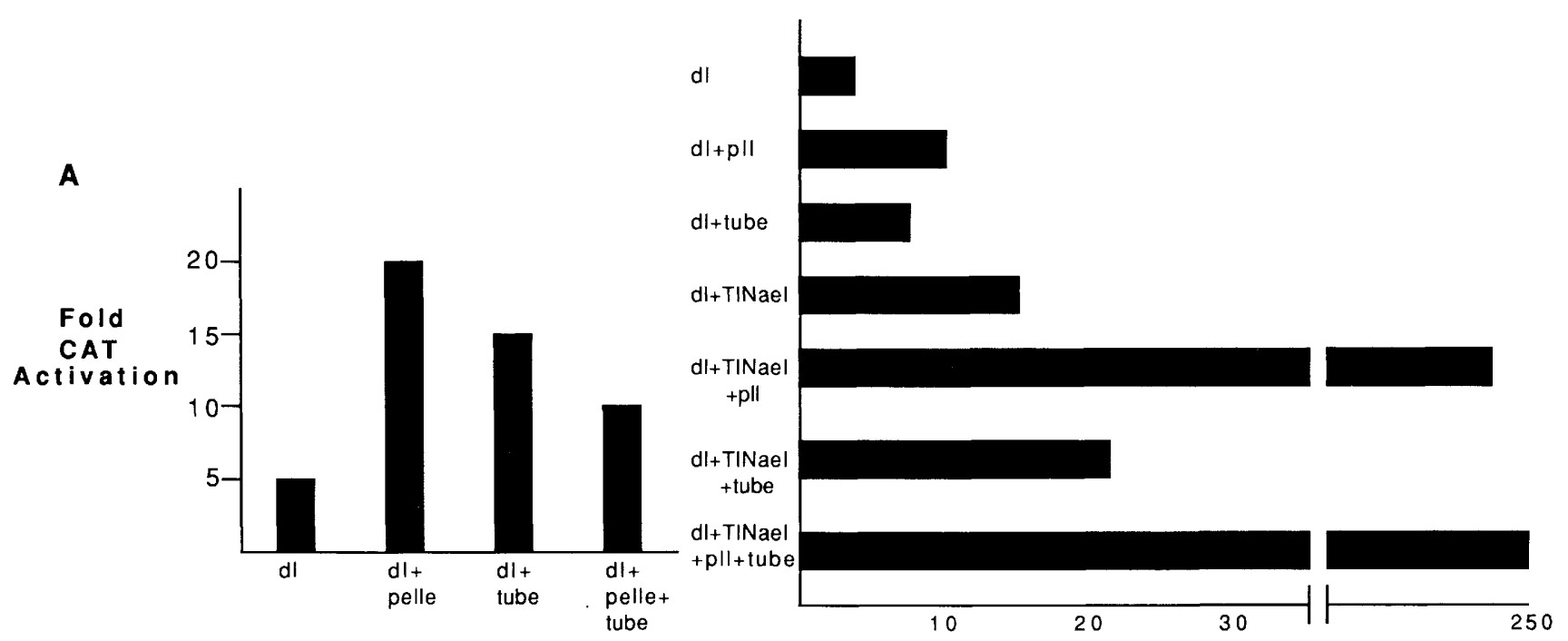

Figure 6. Activity of $\mathrm{dl}$ in the presence of tube and pll. $(A)$ Schneider cells were cotransfected with $0.4 \mu \mathrm{g}$ of $d l$ expression vector, 3.0 $\mu \mathrm{g}$ of pll expression vector, $3.0 \mu \mathrm{g}$ of tube expression vector, $1.0 \mu \mathrm{g}$ of the zen-CAT200 reporter plasmid, and pAct5C to bring the concentration of expression vector to $7.0 \mu \mathrm{g}$. The activation values are expressed relative to cotransfections containing the actin $5 \mathrm{C}$ expression vector without an insert. (B) Schneider cells were transfected with $0.4 \mu \mathrm{g}$ of $d l$ expression vector, $2.0 \mu \mathrm{g}$ of $\mathrm{pll}$ expression vector, $2.0 \mu \mathrm{g}$ of tube expression vector, $2.0 \mu \mathrm{g}$ of $T 1 \mathrm{NaeI}$ expression vector, $1.0 \mu \mathrm{g}$ of the zen-CAT200 reporter plasmid, and pAct5C to bring the concentration of expression vector to $7.0 \mu \mathrm{g}$.

activation brought about by TINaeI plus pll, which may reflect the fact that tube is present endogenously in Schneider cells (see Norris and Manley 1995b).

pll can enhance the activity of a GAL4-tube fusion protein

As mentioned above, $p l l$ has been shown to phosphorylate tube but not $\mathrm{dl}$ in vitro (Grosshans et al. 1994). In addition, we showed that tube can colocalize with $\mathrm{dl}$ to the nucleus, where it has weak transcriptional activating potential. This led us to suggest that tube may function, at least in part, as a coactivator of $\mathrm{dl}$. These properties of tube raise the possibility that it, rather than $\mathrm{dl}$, could be the target of TlNael-activated pll. To test this we utilized the ActGAL4-tube expression vector we described previously. This construct consists of the tube coding region fused to a fragment encoding the GAL4 DNAbinding domain, and the resulting fusion protein was shown to activate transcription from a promoter containing GAL4 binding sites three- to fourfold (Norris and Manley 1995b).

ActGAL4-tube was cotransfected into Schneider cells with ActFlu-pll, Act-TlNaeI, or the two together. All cotransfections contained a reporter plasmid with five GAL4 binding sites controlling expression to the CAT gene (G5E1bTATA-CAT; Colgan et al. 1993), and the results are shown in Figure 7A. Expression of either pll or TlNaeI alone had no significant effect on the activity of GAL4-tube. However, expression of pll plus TlNaeI resulted in a striking 70-fold activation of CAT expression by GAL4-tube. This effect was specific for GAL4-tube, as expression of pll and TlNaeI did not enhance the activity of either GAL4-VP16 (Fig. 7B) or a construct containing only the GAL4 DNA-binding domain (results not shown). Activation was also completely dependent on the presence of GAL4 sites in the reporter plasmid (results not shown). To determine whether this effect required a functional tube protein we used a GAL4-tube2 fusion construct. The tube 2 protein has a single amino acid change of glutamate to lysine at residue 140, which inactivates the protein in embryos (Letsou et al. 1993) and in transfected cells (Norris and Manley 1995b). Figure $7 \mathrm{C}$ shows that no activation of CAT expression was observed when ActGAL4-tube2 was cotransfected with ActFlu-pll and Act-TlNaeI. Although we have not measured accumulation of the GAL4-tube proteins, expression of tube and tube 2 in Schneider cells is comparable (Norris and Manley 1995b).

\section{pll kinase activity is required for signaling}

To determine whether the effects of pll expression we observed reflected phosphorylation, a pll mutant that lacks kinase activity was tested. When the lysine residue at position 240 in the catalytic domain is changed to arginine (K240R), a mutation predicted to abolish enzymatic activity, the resulting protein could not rescue $\mathrm{pll}$ null embryos (Shelton and Wasserman 1993). A pll cDNA containing this mutation was cloned into the actin 5C expression vector, Act-p1lK240R, which was cotransfected with Act-dl, Act-dl plus Act-TlNaeI (Fig. 
Norris et al.

Figure 7. Activity of GAL4-tube fusion proteins in the presence of pll and Toll. Schneider cells were cotransfected with either $3.0 \mu \mathrm{g}$ of GAL4-tube $(A)$ or $1.0 \mathrm{ng}$ GAL4-VP16 $(B)$ or $3.0 \mu \mathrm{g}$ GAL4-tube2 $(C)$ expression vector, $3.0 \mu \mathrm{g}$ of pll expression vector, $1.0 \mu \mathrm{g}$ of $T / \mathrm{NaeI}$ expression vector, $1.0 \mu \mathrm{g}$ of the G5ElbTATA-CAT reporter plasmid, and pAct5C to bring the concentration of expression vector to $7.0 \mu \mathrm{g}$. Activation values are expressed relative to cotransfections containing the actin $5 \mathrm{C}$ expression vector without an insert. $(B)$ As a control to ensure that a lack of response was not attributable to a factor limiting for expression in the presence of the strong activator GAL4-VP16, cells were also transfected with $5.0 \mathrm{ng}$ of the GAL4-VP16 expression vector.

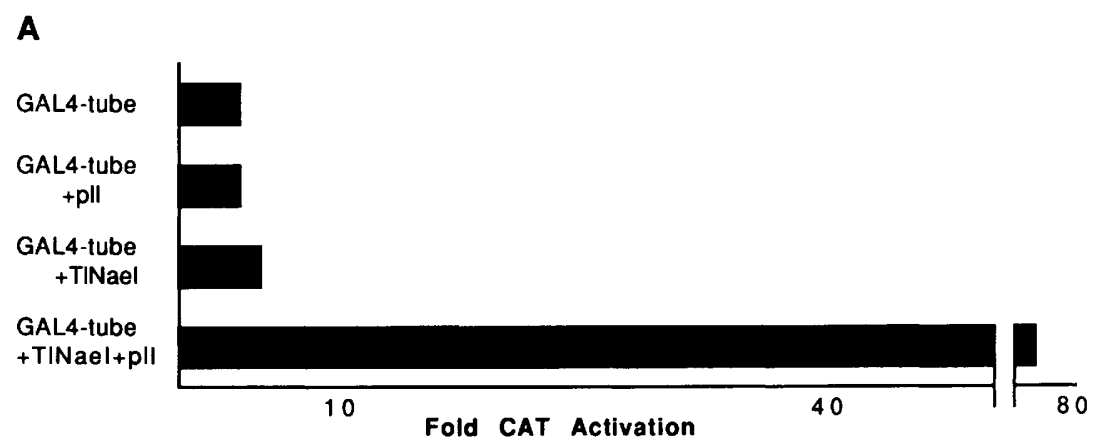

B

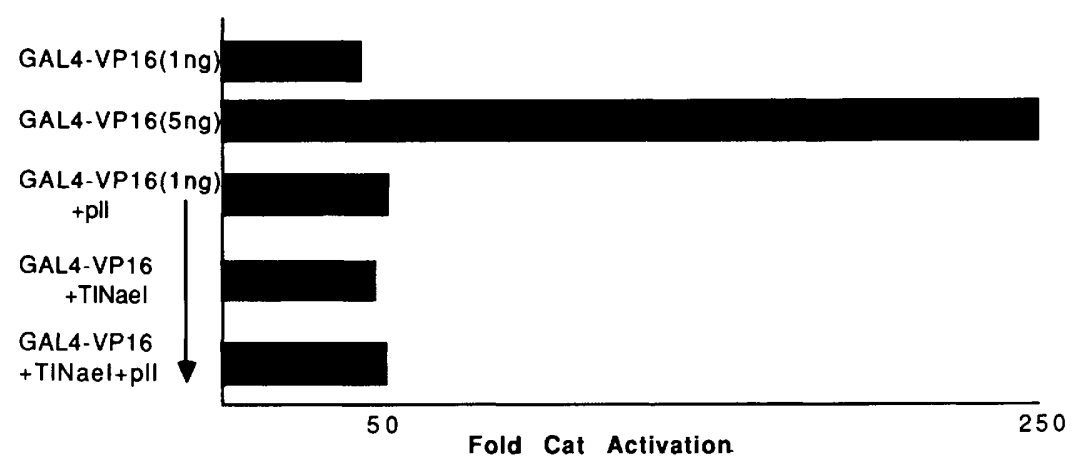

C

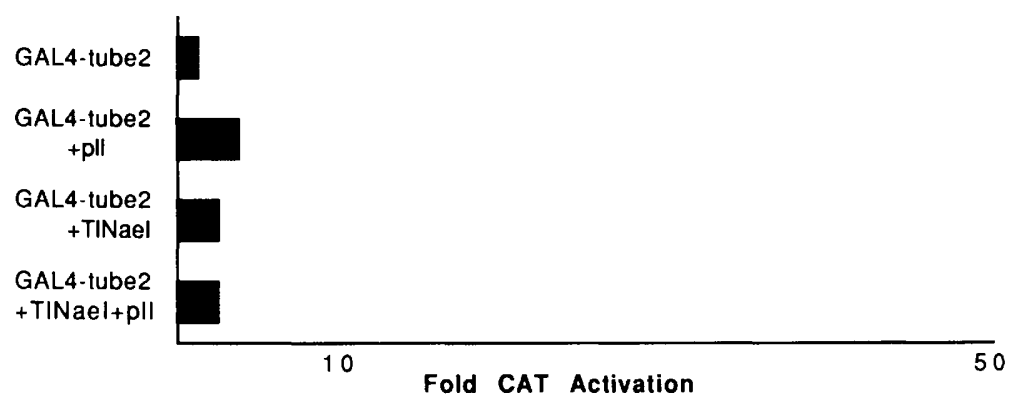

8A), or ActGAL4-tube plus Act-T1NaeI (Fig. 8B). The results show that pllK240R did not, by itself, enhance $\mathrm{dl}$ activity, nor did it synergistically activate dl or GAL4 tube in the presence of TlNaeI. In fact, a reduction in both $\mathrm{dl}$ and GAL4-tube activity was observed when pllK240R and TINaeI were coexpressed, which likely reflects a dominant-negative effect of the mutant kinase (see Discussion). To determine whether pllK240R could relocalize $\mathrm{dl}$ to the nucleus, immunofluorescence assays were performed. Figure $8 \mathrm{C}$ shows that dl remained localized primarily in the cytoplasm in the presence of pllK240R. Therefore, the K240R mutation abolishes the ability of pll to enhance both nuclear localization and transcriptional activity.

\section{Discussion}

Models for activation of dl nuclear transport and transcriptional activity

The data presented here provide new insights into how components of the dl signaling pathway can interact with one another during signal transduction. These interactions, as well as others suggested by previous studies, are summarized schematically in Figure 9. Prior to ligand binding (Fig. 9, top), we suggest that Toll's intracellular domain is in a conformation where the active domain, the region that is similar to IL- $1 R$, is masked by the inhibitory domain, the region unique to Toll. The tube and pll proteins are complexed (Grosshans et al. 1994; Galindo et al. 1995) and localized near the plasma membrane, whereas the $\mathrm{dl}$ and cactus proteins are complexed (Geisler et al. 1992; Kidd 1992) in the cytoplasm. Once Toll is activated a conformational change occurs in the intracellular domain resulting in exposure of the active domain.

The intracellular interactions that follow Toll activation are still not clear, although several possible mechanisms of signal transmission from Toll to dl are possible. In a previous study (Norris and Manley 1992), we presented evidence that Toll can activate an intracellular 
A

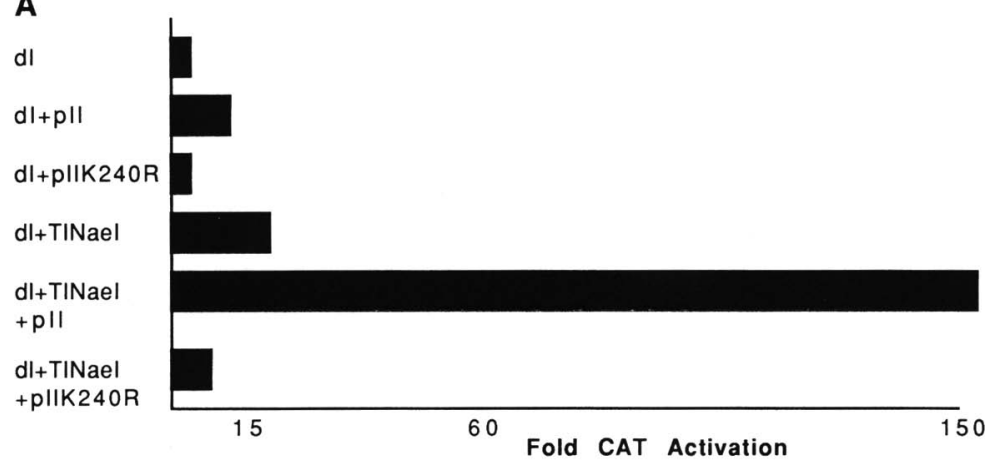

B

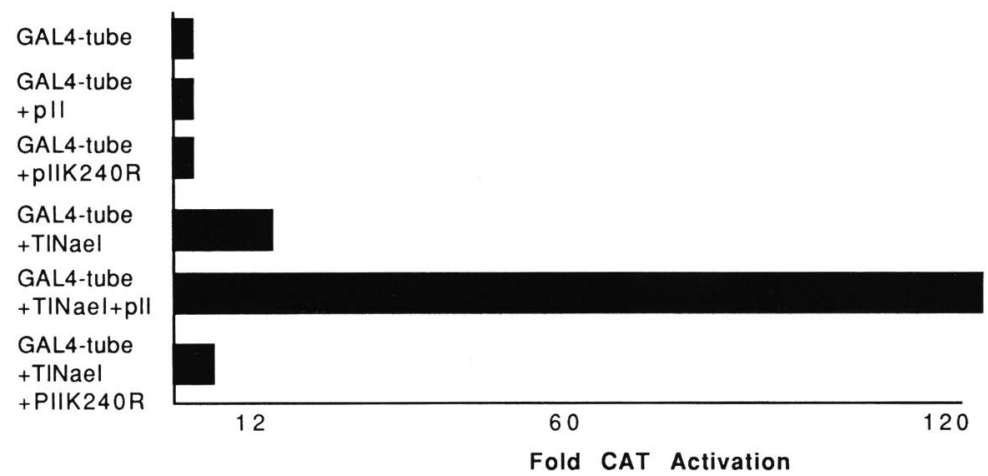

C d I
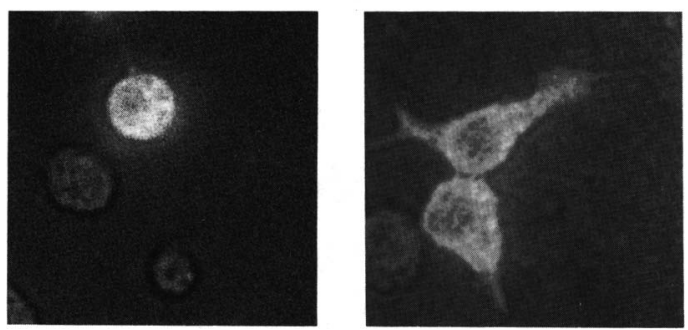

Figure 8. Activity of $\mathrm{dl}$ and GAL4-tube in the presence of pllK240R and TlNaeI. (A) Schneider cells were cotransfected with $0.4 \mu \mathrm{g}$ of $d 1$ expression vector, $3.0 \mu \mathrm{g}$ of pll or pllK240R expression vector, $1.0 \mu \mathrm{g}$ of TINaeI expression vector, $1.0 \mu \mathrm{g}$ of the zen-CAT200 reporter plasmid, and pAct5C to bring the final concentration of expression vector to $7.0 \mu \mathrm{g}$. (B) Schneider cells were cotransfected with $3.0 \mu \mathrm{g}$ of GAL4-tube expression vector, $3.0 \mu \mathrm{g}$ of $p l l$ or $p l l \mathrm{~K} 240 \mathrm{R}$ expression vector, $1.0 \mu \mathrm{g}$ of T/NaeI expression vector, $1.0 \mu \mathrm{g}$ of the G5E1bTATACAT reporter plasmid, and pAct5C to bring the concentration of expression vector to $7.0 \mu \mathrm{g}$. All activation values $(A, B)$ are expressed relative to cotransfections containing the actin $5 \mathrm{C}$ expression vector without an insert. $(C)$ Schneider cells were cotransfected with 0.4 $\mu \mathrm{g}$ of $d l$ expression vector alone or with $4 \mu \mathrm{g}$ of $p l l \mathrm{~K} 240 \mathrm{R}$ expression vector. Cells were fixed and stained with anti-dl and TRITC-conjugated antibodies. signaling pathway in Schneider cells that utilizes PKA to enhance dl nuclear localization and transcriptional activity (Fig. 9, bottom left; see also below). Recent genetic studies (Grosshans et al. 1994; Galindo et al. 1995) have suggested that Toll activates a signaling pathway that utilizes pll to enhance dl nuclear transport. These studies also provided evidence that tube activity is required upstream of pll, perhaps to facilitate transmission of the signal from Toll to pll (Fig. 9, bottom center). Finally, the results presented here also suggest that Toll activates pll. However, pll then phosphorylates and activates tube, which translocates to the nucleus with $\mathrm{dl}$, and tube thus has a function downstream of pll (Fig. 9, bottom right). Because tube is expressed endogenously in Schneider cells, its activity may also be required upstream of pll.

It is conceivable that the above mechanisms may reflect different aspects of a single pathway. By this view, we would envision an integrated model by which the tube/pll complex interacts with the Toll active domain, resulting in activation of pll. pll then phosphorylates tube, which causes the disruption of the tube/pll/Toll complex. tube is then free to translocate to the nucleus with $\mathrm{dl}$ (following its dissociation from cactus), pll is free to modify other proteins (e.g., $\mathrm{dl}$ or cactus), and Toll is free in some way to signal the activation of PKA. Activated PKA phosphorylates $\mathrm{dl}$, aiding in the dissociation of the $\mathrm{dl} /$ cactus complex, or in $\mathrm{dl}$ nuclear transport, and enhancing $\mathrm{dl}$ transcriptional activity. However, it is also possible that the three pathways depicted in Figure 9 reflect distinct mechanisms that occur under different circumstances. For example Toll, pll, tube, and dl are known to function not only in the early embryo during $\mathrm{D} / \mathrm{V}$ patterning but also in larval and adult fat bodies during the immune response (Lemaitre et al. 1995). As with rel/NF-kB proteins in mammals, there may be multiple ways to activate such proteins in Drosophila.

\section{The tube/pll/Toll complex: transmission of the signal}

We have presented results indicating that an interaction, either direct or indirect, occurs between pll and Toll upon exposure of Toll's active domain by deletion of the inhibitory domain. We suggest that naturally a ligandinduced conformational change in Toll similarly exposes the active domain. In our system, where Toll is activated in the absence of ligand [presumably by overexpression and aggregation (see Norris and Manley 1995b)], this conformational change may not occur efficiently, and full activation thus requires deletion of the inhibitory domain. This type of effect has also been observed with the Fas receptor and its associated protein FADD. In this case, deletion of 15 carboxy-terminal amino acids from Fas was shown to result in a stronger interaction with FADD in vitro (Chinnaiyan et al. 1995).

Several lines of evidence support the interaction of pll with other components of the signaling pathway. Genetic analysis of pll alleles has suggested that pll may participate in a multicomponent complex. Unlike most 


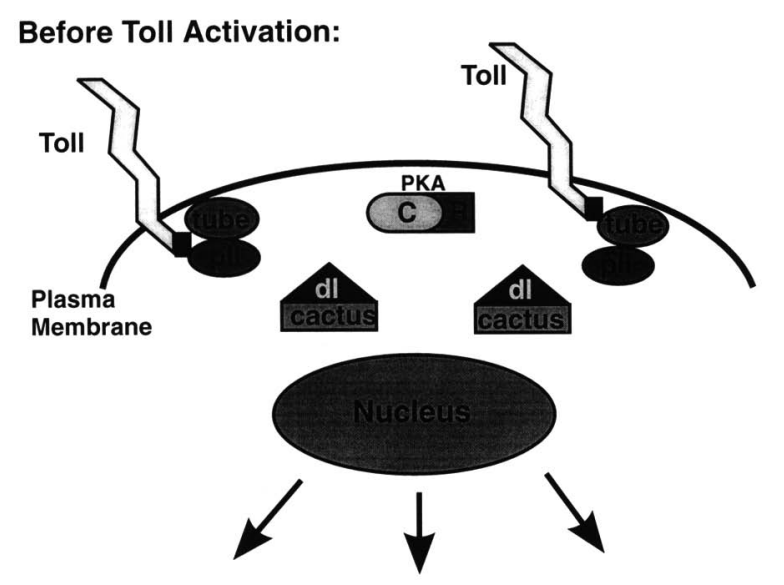

After Toll Activation:

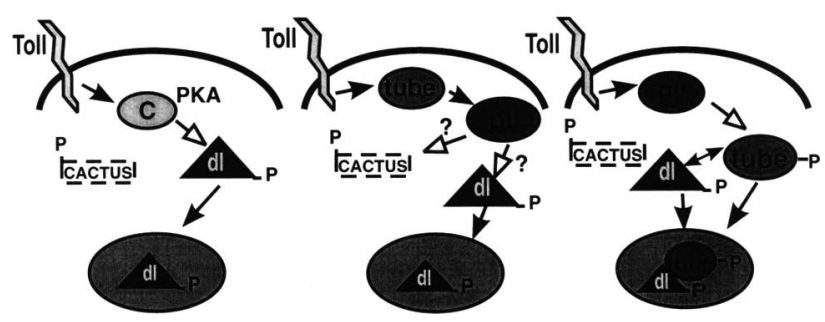

Figure 9. Models for nuclear transport and activation of $\mathrm{dl}$. Before activation (top), the Toll active domain is masked by its inhibitory domain (solid box), tube and pll are complexed at the plasma membrane, and $\mathrm{dl}$ is held in the cytoplasm by association with cactus. After Toll is activated, the intracellular active domain is exposed, resulting in the activation of intracellular signaling pathways (bottom). These pathways may utilize PKA (left), pll (center and right), or both to enhance dl nuclear transport and activity. tube may function upstream of pll (center), downstream of pll (right) or at both positions in the pathway (see text). Open arrowheads indicate phosphorylations.

of the other $d l$ group genes, several pll alleles are cold sensitive, which is often interpreted as suggesting participation of the protein in a complex (Hecht and Anderson 1993). In addition, several pll alleles are antimorphoic, producing a stronger dorsalized phenotype when expressed with a weak pll allele than when the same pll allele is expressed with a pll deficiency (Hecht and Anderson 1993). Such alleles may interfere with the activity of the signaling pathway by directly and nonproductively interacting with another component. Our results with the pllK240R mutant also provide support for interaction of pll with other components of the signaling pathway. If pll participates in a complex with Toll, and its kinase activity is required for disrupting this complex, then signal transduction would be blocked if the Toll/pll complex could not be disrupted. In this case, dl activity in the presence of pllK240R and Toll should be lower than $\mathrm{dl}$ activity in the presence of Toll alone because no signaling from Toll could take place. Consistent with this, dl, or GAL4-tube, activity in the presence of pllK240R and activated Toll (TINaeI) was lower than in the presence of activated Toll alone. This reduction in $\mathrm{dl}$ activity could result, for example, from an inability of Toll to activate PKA, and therefore $\mathrm{dl}$, as Toll would remain complexed with pllK240R. In the case of GAL4tube, pllK240R would be unable to phosphorylate tube, and therefore GAL4-tube would remain complexed with pllK240R and Toll.

Previous studies suggested that tube has another function in regulating $\mathrm{dl}$ : tube may function as a transcriptional coactivator, as it colocalizes with $\mathrm{dl}$ in the nucleus and a GAL4-tube fusion protein can activate transcription (Norris and Manley 1995b). Because pll phosphorylates tube in vitro (Grosshans et al. 1994), phosphorylation could provide a mechanism for activation of tube. Because tube is expressed endogenously in Schneider cells, activation of dl by pll could function, at least in part, through pll's activation of tube. Phosphorylation of tube could first provide the mechanism for the dissociation of the tube/pll/Toll complex and then enhance its nuclear transport, transcriptional activity, or both. The striking activation of GAL4-tube by activated pll supports this model. These results raise the possibility that, perhaps for a limited number of target genes, a significant function of $\mathrm{dl}$ may be to recruit phosphorylated tube to the promoter.

\section{The dl/cactus complex: Activation of $d l$}

Our previous work has suggested that phosphorylation of $\mathrm{dl}$ by PKA can facilitate $\mathrm{dl}$ nuclear transport and enhance its transcriptional activity (Norris and Manley 1992). PKA appears to function through the conserved PKA site in dl's rel homology domain (RHD), as mutation of this site resulted in a primarily cytoplasmic protein (dlQ) that was unresponsive to PKA (or Toll) expression (Norris and Manley 1992). Somewhat unexpectedly, this site also appears to be required for pll-induced dl nuclear transport, as expression of pll could not enhance nuclear localization of dlQ. We suggest several possible explanations for this finding. First, it is conceivable that pll and PKA recognize the same or related sequences such that the same serine would be modified by each. Second, pll could phosphorylate and activate an endogenous PKA-like kinase, which would then phosphorylate dl. Third, the dlQ mutation could have an unexpected effect on dl not related to pll phosphorylation.

Although in mammalian systems attention has recently centered on $I_{\kappa} B$, phosphorylation of NF- $\mathrm{B}$ may also be involved in regulating NF- $\mathrm{BB} / \mathrm{I} \mathrm{KB}$ complex dissociation and/or NF- $\mathrm{B}$ activity. The $\mathrm{p} 65$ subunit of NF- $\mathrm{kB}$ is phosphorylated with the same kinetics as I $\mathrm{B}$ upon cytokine stimulation of HeLa cells, suggesting that both I $\mathrm{B}$ and NF- $\mathrm{B}$ B have to be phosphorylated for complex dissociation (Naumann and Scheidereit 1994). Phosphorylation of p65 appears to play a subsequent role in regulation of NF- $\kappa B$ activity (Naumann and Scheidereit 1994; Neumann et al. 1995). Phosphorylated p65 isolated from HeLa cells, or phosphorylated in vitro (by PKA), exhibits enhanced DNA-binding activity relative to unphosphorylated p65, suggesting that phosphorylation, perhaps by 
PKA, is important for optimal activity of p65 (Naumann and Scheidereit 1994).

The results presented here suggest that signal transduction from Toll occurs through pll and tube. The interaction between activated Toll and pll may be direct or may require other components of the signal transduction pathway that have (e.g., tube) or have not been identified. Examination of factors that can directly interact with Toll's intracellular domain, specifically the IL-IR homology region, should clarify the nature of this interaction. Our data have shown that signaling from pll can occur, at least in part, via phosphorylation of tube. Although identification of other proteins that pll modifies may be required to clarify the full role of pll in enhancing $\mathrm{dl}$ nuclear transport and activity, our results have provided mechanistic insights into this genetically well-defined signal transduction pathway.

\section{Materials and methods}

\section{Recombinant plasmids}

All expression vectors were derived from a plasmid that contains the Drosophila actin 5C promoter and poly(A) site, pAct5C, which has been described in detail (Han et al. 1989). The ActFlu-pll and Act-pllK240R expression vectors were constructed from the pll cDNA clones kindly provided by $\mathrm{S}$. Wasserman (Shelton and Wasserman 1993). Constructs both with and without an influenza virus $\mathrm{HAl}$ epitope tag were made by standard cloning procedures. The actin $5 \mathrm{C}$ expression vector containing the HAl epitope tag was described previously (pActPflu; Han and Manley 1993). The GAL4-VP16 expression vector was provided by J. Colgan (Colgan et al. 1993). All other expression vectors and reporter constructs used in these studies have been described previously (Han et al. 1989; Rushlow et al. 1989; Norris and Manley 1992, 1995b).

\section{DNA transfection and transient expression assay}

Drosophila Schneider L2 cells were grown and transfected as described previously (Han et al. 1989). All transfections contained the indicated amount of each expression vector and variable amounts of pAct $5 \mathrm{C}$ to bring the total amount of expression vector to $7.0 \mu \mathrm{g}$. All transfections for measuring CAT activities also contained $1.0 \mu \mathrm{g}$ of the zen-CAT200 reporter plasmid and $2.0 \mu \mathrm{g}$ of the copia long terminal repeat (LTR)-lacZ plasmid (copia-Bgal) as an internal control. All transfections were performed in duplicate, and $\beta$-galactosidase and CAT activities were measured as described previously (Han et al. 1989). Normalized CAT activities were calculated by determining CAT/ $\beta$-gal activity ratios and averaging the values from several independent transfections.

\section{Staining of cells}

Cell staining was performed essentially as described previously (Norris and Manley 1992). Briefly, cells were fixed and incubated with anti-dl primary antibodies (Norris and Manley 1995b). Cells were then washed three times, and dl protein was visualized by incubation with the anti-rat TRITC-conjugated secondary antibodies.

\section{Acknowledgments}

We are grateful to S. Wasserman, K. Han, and J. Colgan for providing plasmids and $\mathrm{M}$. Levine for comments on the manuscript. We thank M. Um for helpful discussions. This work was supported by National Institutes of Health grant GM-37971.

The publication costs of this article were defrayed in part by payment of page charges. This article must therefore be hereby marked "advertisement" in accordance with 18 USC section 1734 solely to indicate this fact.

\section{References}

Aikalay, I., A. Yaron, A. Hatzubai, S. Jung, A. Avraham, O. Gerlitz, I. Pashut-Lavon, and Y. Ben-Neriah. 1995. In vivo stimulation of IkB phosphorylation is not sufficient to activate NF-кB. Mol. Cell. Biol. 15: 1294-1301.

Beg, A.A. and A.S. Baldwin, Jr. 1993. The IкB proteins: Multifunctional regulators of Rel NF- $\mathrm{KB}$ transcription factors. Genes \& Dev. 7: 2064-2070.

Beg, A.A., T.S. Finco, P.V. Nantermet, and A.S. Baldwin, Jr. 1993. Tumor necrosis factor and interleukin-1 lead to phosphorylation and loss of $\mathrm{I} \kappa \mathrm{B}$ : A mechanism for NF- $\mathrm{KB}$ activation. Mol. Cell. Biol. 13: 3301-3310.

Belvin, M.P., Y. Jin, and K.V. Anderson. 1995. Cactus protein degradation mediates Drosophila dorsal-ventral signaling. Genes \& Dev. 9: 783-793.

Brown, K., S. Gerstberger, L. Carlson, G. Franzoso, and U. Siebenlist. 1995. Control of IKB- $\alpha$ proteolysis by site-specific signal-induced phosphorylation. Science 267: 1485-1488.

Chinnaiyan, A.M., K. O'Rourke, A. Tewari, and V.M. Dixit. 1995. FADD, a novel death domain-containing protein, interacts with the death domain of Fas and initiates apoptosis. Cell 81: 505-512.

Colgan, J., S. Wampler, and J.L. Manley. 1993. Interaction between a transcriptional activator and transcription fact IIB in vivo. Nature 362: 549-553.

DiDonato, J.A., F. Mercurio, and M. Karin. 1995. Phosphorylation of $I_{\kappa} B \alpha$ precedes but is not sufficient for its dissociation from NF-кB. Mol. Cell. Biol. 15: 1302-1311.

Finco, T.S., A.A. Beg, and A.S. Baldwin, Jr. 1994. Inducible phosphorylation of $I \kappa B \alpha$ is not sufficient for its dissociation from NF- $\mathrm{KB}$ and is inhibited by protease inhibitors. Proc. Natl. Acad. Sci. 91: 11884-11888.

Galindo, R.L., D.N. Edwards, S.K.H. Gillespie, and S.A. Wasserman. 1995. Interaction of the pelle kinase with the membrane-associated protein tube is required for transduction of the dorsoventral signal in Drosophila embryos. Development 121: 2209-2218.

Geisler, R., A. Bergmann, Y. Hiromi, and C. Nüsslein-Volhard. 1992. cactus, a gene involved in dorsoventral pattern formation of Drosophila, is related to the ІкВ gene family of vertebrates. Cell 71: 613-621.

Ghosh, S. and D. Baltimore. 1990. Activation in vitro of NfкB by phosphorylation of its inhibitor IкB. Nature 344: 678-682.

Gillespie, S.K. and S.A. Wasserman. 1994. dorsal, a Drosophila Rel-like protein, is phosphorylated upon activation of the transmembrane protein Toll. Mol. Cell. Biol. 14: 3559-3568.

Govind, S. and R. Steward. 1991. Dorsoventral pattern formation in Drosophila: Signal transduction and nuclear targeting. Trends Genet. 7: 119-125.

Grosshans, J., A. Bergmann, P. Haffter, and C. Nüsslein-Volhard. 1994. Activation of the kinase Pelle by Tube in the dorsoventral signal transduction pathway of Drosophila embryo. Nature 372: 563-566.

Han, K. and J.L. Manley. 1993. Transcriptional repression by the Drosophila Even-skipped protein: Definition of a minimal repression domain. Genes \& Dev. 7: 491-503. 
Han, K., M.S. Levine, and J.L. Manley. 1989. Synergistic activation and repression of transcription by Drosophila homeobox proteins. Cell 56: 573-583.

Hashimoto, C., K.L. Hudson, and K.V. Anderson. 1988. The Toll gene of Drosophila, required for dorsal-ventral embryonic polarity, appears to encode a transmembrane protein. Cell 52: $269-279$.

Hashimoto, C., S. Gerttula, and K.V. Anderson. 1991. Plasma membrane localization of the Toll protein in the syncytial Drosophila embryo: Importance of transmembrane signaling for dorsal-ventral pattern formation. Development 111: 10201028 .

Hecht, P.M. and K.V. Anderson. 1993. Genetic characterization of tube and pelle, genes required for signaling between Toll and dorsal in the specification of the dorsal-ventral pattern of the Drosophila embryo. Genetics 135: 405-417.

Heguy, A., C.T. Baldari, G. Macchia, J.L. Telford, and M. Melli. 1992. Amino acids conserved in interleukin-1 receptors (ILIRs) and the Drosophila Toll protein are essential for IL-1R signal transduction. J. Biol. Chem. 267: 2605-2609.

Henkel, T., T. Machleidt, I. Alkalay, M. Kronke, Y. Ben-Nerish, and P.A. Baeuerle. 1993. Rapid proteolysis of IкB- $\alpha$ is necessary for activation of transcription factor NFkB. Nature 365: 182-185.

Ip, Y.T., M. Reach, Y. Engstrom, L. Kadalayil, H. Cai, S. Gonzalez-Crespo, K. Tatei, and M. Levine. 1993. Dif, a dorsal-related regulatory gene that mediates an immune response in Drosophila. Cell 75: 753-763.

Kidd, S. 1992. Characterization of the Drosophila cactus locus and analysis of interactions between cactus and dorsal proteins. Cell 71: 623-635.

Lamaitre, B., M. Meister, S. Govind, P. Georgel, R. Seward, J.M. Reichart, and J.A. Hoffmann. 1995. Functional analysis and regulation of nuclear import of dorsal during the immune response in Drosophila. EMBO I. 14: 536-545.

Letsou, A., S. Alexander, K. Orth, and S.A. Wasserman. 1991. Genetic and molecular characterization of tube, a Drosophila gene maternally required for embryonic dorsoventral polarity. Proc. Natl. Acad. Sci. 88: 810-814.

Letsou, A., S. Alexander, and S.A. Wasserman. 1993. Domain mapping of tube, a protein essential for dorsoventral patterning of the Drosophila embryo. EMBO I. 12: 3449-3458.

Miyamoto, S., M. Maki, M.J. Schmitt, M. Hatanaka, and I.M. Verma. 1994. Tumor necrosis factor $\alpha$-induced phosphorylation of $\mathrm{I}_{\kappa} \mathrm{B} \alpha$ is a signal for its degradation but not dissociation from NF-кB. Proc. Natl. Acad. Sci. 91: 12740-12744.

Morisato, D. and K.V. Anderson. 1994. The spätzle gene encodes a component of the extracellular signaling pathway establishing the dorsal-ventral pattern of the Drosophila embryo. Cell 76: 677-688.

Naumann, M. and C. Scheidereit. 1994. Activation of NF-kB in vivo is regulated by multiple phosphorylations. EMBO I. 13: 4597-4607.

Neumann, M., T. Grieshammer, S. Chuvpilo, B. Kneitz, M. Lohoff, A. Schimpl, B.R. Franza, Jr., and E. Serfling. 1995. RelA/ p65 is a molecular target for the immunosuppressive action of protein kinase A. EMBO I. 14: 1991-2004.

Norris, J.L. and J.L. Manley. 1992. Selective nuclear transport of the Drosophila morphogen dorsal can be established by a signaling pathway involving the transmembrane protein Toll and protein kinase A. Genes \& Dev. 6: 1654-1667.

- 1995a. Regulation of the nuclear transport and activity of the Drosophila morphogen Dorsal. In Inducible gene expression, Volume 2 (ed. P.A. Baeuerle), pp. 243-265. Birkhäuser, Boston, MA.

1995b. Regulation of dorsal in cultured cells by Toll and tube: tube function involves a novel mechanism. Genes \& Dev. 9: 358-369.

Palombella, V.J., O.J. Rando, A.L. Goldberg, and T. Maniatis. 1994. The ubiquitin-proteasome pathway is required for processing the NF- $\mathrm{KB} 1$ precursor protein and the activation of NF-кB. Cell 78: 773-785.

Roth, S., D. Stein, and C. Nüsslein-Volhard. 1989. A gradient of nuclear localization of the dorsal protein determines dorsoventral pattern in the Drosophila embryo. Cell 59: 11891202.

Roth, S., Y. Hiromi, D. Godt, and C. Nüsslein-Volhard. 1991. cactus, a maternal gene required for proper formation of the dorsoventral morphogen gradient in Drosophila embryos. Development 112: 371-388.

Rushlow, C. and R. Warrior. 1992. The Rel family of proteins. BioEssays 14: 89-95.

Rushlow, C., K. Han, J.L. Manley, and M. Levine. 1989. The graded distribution of the dorsal morphogen is initiated by selective nuclear transport in Drosophila. Cell 59: 11651177.

Schneider, D.S., K.L. Hudson, T.-Y. Lin, and K.V. Anderson. 1991. Dominant and recessive mutations define functional domains of Toll, a transmembrane protein required for dorsal-ventral polarity in the Drosophila embryo. Genes \& Dev. 5: 797-807.

Schneider, D.S., Y. Jin, D. Morisato, and K.V. Anderson. 1994. A processed form of the spätzle protein defines dorsal-ventral polarity in the Drosophila embryo. Development 120: 12431250.

Shelton, C.A. and S.A. Wasserman. 1993. pelle encodes a protein kinase required to establish dorsoventral polarity in the Drosophila embryo. Cell 72: 515-525.

Shirakawa, F., U. Yamashita, M. Chedid, and S.B. Mizel. 1988. Cyclic AMP - an intracellular second messenger for interleukin 1. Proc. Natl. Acad. Sci. 85: 8201-8205.

Shirakawa, F., M. Chedid, J. Suttles, B.A. Pollok, and S.B. Mizel. 1989. Interleukin 1 and cyclic AMP induce $\kappa$ immunoglobulin light-chain expression via activation of an NF-кB-like DNA-binding protein. Mol. Cell. Biol. 9: 959-964.

Siebenlist, U., K. Brown, and G. Franzoso. 1995. NF-kB: A mediator of pathogen and stress responses. In Inducible gene expression, Volume 1 (ed. P.A. Bauerle), pp. 93-141. Birkhäuser, Boston, MA.

Stein, D. and C. Nüsslein-Volhard. 1992. Multiple extracellular activities in Drosophila egg perivitelline fluid are required for establishment of embryonic dorsal-ventral polarity. Cell 68: $429-440$.

Stein, D., S. Roth, E. Vogelsang, and C. Nüsslein-Volhard. 1991. The polarity of the dorsoventral axis in the Drosophila embryo is defined by an extracellular signal. Cell 65: 725-735.

Steward, R. 1989. Relocalization of the dorsal protein from the cytoplasm to the nucleus correlates with its function. Cell 59: $1179-1188$.

Traenckner, E.B.-M., S. Wilk, and P.A. Baeuerle. 1994. A proteasome inhibitor prevents activation of NF- $\mathrm{KB}$ and stabilizes a newly phosphorylated form of $\mathrm{I}_{\kappa} \mathrm{B} \alpha$ that is still bound to NF-кB. EMBO $/$. 13: 5433-5441.

Traenckner, E.B.-M., H.L. Pahl, T. Henkel, K.N. Schmidt, S. Wilk, and P.A. Baeuerle. 1995. Phosphorylation of human I B $-\alpha$ on serines 32 and 36 controls IкB- $\alpha$ proteolysis and $\mathrm{NF}-\mathrm{kB}$ activation in response to diverse stimuli. EMBO $J$ 14: $2876-2883$.

Whalen, A.M. and R. Steward. 1993. Dissociation of the DorsalCactus complex and phosphorylation of the Dorsal protein correlate with the nuclear localization of Dorsal. J. Cell Biol. 123: $523-534$. 


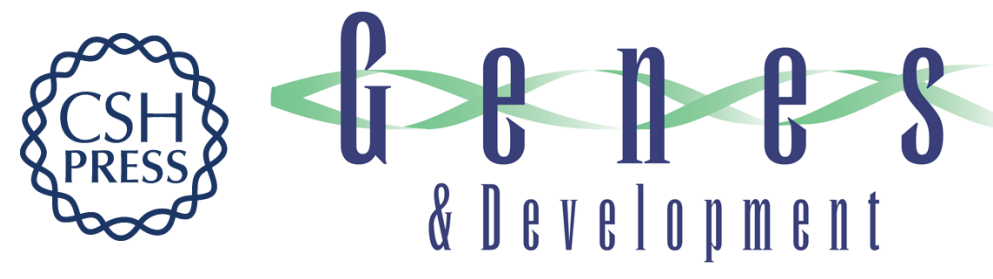

\section{Functional interactions between the pelle kinase, Toll receptor, and tube suggest a mechanism for activation of dorsal.}

$\mathrm{J} L$ Norris and $\mathrm{J} L$ Manley

Genes Dev. 1996, 10:

Access the most recent version at doi:10.1101/gad.10.7.862

References This article cites 49 articles, 22 of which can be accessed free at: http://genesdev.cshlp.org/content/10/7/862.full.html\#ref-list-1

License

Email Alerting

Service

Receive free email alerts when new articles cite this article - sign up in the box at the top right corner of the article or click here.

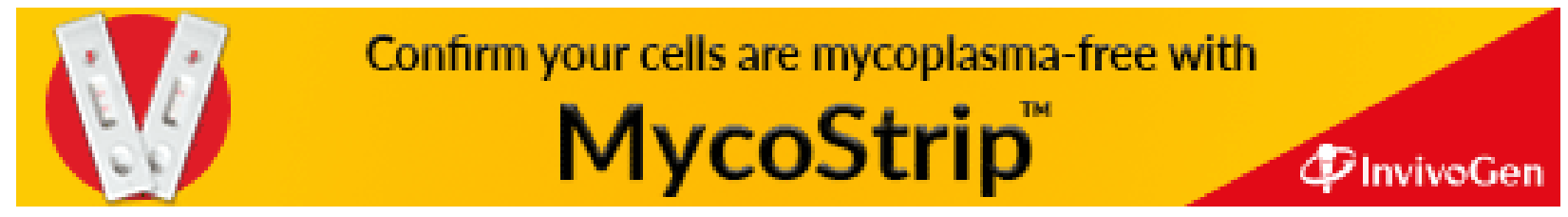

